NEWS

Drug targeting: is race enough?

\section{WASHINGTON DC}

The expected approval in the United States of the first drug targeted to a specific racial group is sparking debate about the future of 'personalized' medicine.

Enthusiasts predict a future in which people are given genetic tests to help choose the drug to which they will respond best. But some experts worry about the precedent of accepting race as a crude marker for underlying biological differences - which could still leave many individuals being treated with drugs that don't work well for them.

Last week, an advisory committee to the Food and Drug Administration (FDA) recommended that BiDil, a drug for congestive heart failure, should be approved for sale with a label designating African Americans as the target population. The FDA usually follows the advice of its experts and is expected to make its decision by 23 June.

Francis Collins, director of the National Human Genome Research Institute in Bethesda, Maryland, says that the drug's effectiveness in blacks is "something to celebrate". Even so, he argues: "We should move without delay from blurry and potentially misleading surrogates for drug response, such as race, to the more specific causes."

$\mathrm{BiDil}$ is a combination of isosorbide dinitrate, used to treat angina, and hydralazine, which lowers blood pressure. It is made by NitroMed of Lexington, Massachusetts. The drug was initially tested in a population that was about two-thirds white and one-third blackby another company. The results weren't persuasive, and the FDA turned down a request for marketing approval in 1997.

But Jay Cohn, a cardiologist at the University of Minnesota, reanalysed the data and found that the black patients had responded much better to the drug.

Cohn and NitroMed were granted a precedent-setting patent on $\mathrm{BiDil}$ as a racially targeted drug, and the company launched a new trial in 1,050 black patients. BiDil reduced deaths by $43 \%$, proving so successful that the trial was stopped early, in 2004.

The drug's anticipated approval has been greeted with enthusiasm by both cardiologists and the drugs industry. "This is the most important advance in the care of black people that we've seen in my lifetime, "Charles Curry, president of the International Society on Hypertension in Blacks, told the FDA.

But Collins is wary of using the "biologically inaccurate and socially dangerous" surrogate of race, rather than pushing researchers and companies to investigate the genetic and environmental factors that determine individual differences in drug response. Even if blacks respond better on average to $\mathrm{BiDil}$ than whites, he points out, the drug will still be ineffective for those who don't possess a particular cardiac physiology or combination of genes. There may also be a minority of whites who would benefit from taking BiDil.

Collins contrasts BiDil with Iressa (gefitinib), the AstraZeneca drug whose effectiveness at treating advanced lung cancer was so
disappointing that theFDA last week restricted its use to current users and patients in clinical trials. Nevertheless, in about $10 \%$ of patients on Iressa, lung tumours shrink rapidly. Japanese patients are three times as likely as whites to fall into this group. But the underlying difference is that patients who respond well have specific mutations in the receptor for epidermal growth factor.

This opens up the possibility of using Iressa to treat people whose tumours have these mutations. "Wouldn't it be unfortunate if at this point all we knew is that there is a better chance of responding if you are Japanese?" says Collins.

But will drug companies have sufficient incentive to go beyond using race or other crude surrogates, when to do so would entail

\title{
Trouble brews over contested trend in hurricanes
}

The debate over whether global warming is making hurricanes worse has been nothing if not stormy.

The issue came to a head in January, when leading US meteorologist Chris Landsea resigned from the Intergovernmental Panel on Climate Change, complaining that a colleague on the panel, Kevin Trenberth, had supported a link between warming and storms in a press conference. Now, just in time for the 2005 hurricane season, Trenberth has clarified his views in print (Science 308, 1753-1754; 2005). He argues that the intensity, if not the frequency, of hurricanes and typhoons will increase as the oceans warm.

The hurricane seasons from 1995 to 2004 have been far above the long-term average in terms of the number of storms and accompanying rainfall. However, most scientists are still

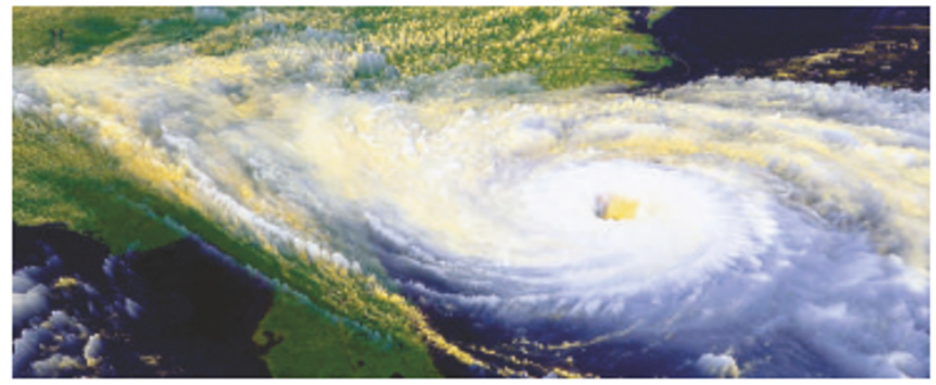

Open season: the latest hurricane analysis will wind up those who say that worsening storms are not related to global warming.

extremely cautious about connecting hurricane activity and global warming. Since satellite detection started 35 years ago, there has been no detectable trend in hurricane frequency, points out modeller Kerry Emanuel of the Massachusetts Institute of Technology in Cambridge, Massachusetts.

But Trenberth, head of the climate analysis section of the National Center for Atmospheric Research in Boulder, Colorado, argues that because the number of hurricanes is relatively small, and fluctuates in cycles of various lengths, proving the existence of a trend from weather records is extremely difficult.

He has looked instead at how hurricanes form. ${ }^{\alpha}$ Trends in human-influenced environ- 
